EESTI NSV TEADUSTE AKADEEMIA TOIMETISED 1955. IV kd., nr. I ИЗВЕСТИЯ АКАДЕМИИ НАУК ЭСТОНСКОИ ССР 1955. ТОМ IV, № 1

\title{
KARTULI LEHEMÄDANIKU (Phytophthora infestans de Bary) ILMUMISE PROGNOOSIMISEST
}

\author{
A. MARLAND, \\ bioloogiateaduste doktor
}

Kõrgete saakide kindlustamisel on määrava tähtsusega taimehaiguste õigeaegne tõrje. Teatud haiguste ilmumist on püütud vastavate ilmastikutegurite põhjal prognoosida, et kindlaks määrata tõrje teostamiseks kohane aeg.

Juba ammu märgati seost kartuli lehemädaniku esinemise ja meteoroloogiliste tegurite, nagu sademete, temperatuuri, udu jt. vahel. Esimene teaduslik uurimus kartuli lehemädaniku prognoosimise kohta meteoroloogiliste andmete alusel teostati v a n Ever d i n g e n i poolt (4), kes empiiriliselt koostas kartuli lehemädaniku lööbimise indeksi, mida tuntakse „hollandi tunnuste” nimetuse all. Selle järgi sõltub lehemädaniku lööbimine neljast ilmastikutegurist: 1) temperatuur eelmisel ööl vähemalt $+10^{\circ} \mathrm{C}, 2$ ) vähemalt 4 tundi udu, 3) pilvitus järgneval päeval vähemalt $80 \%$ ja 4) $0,1 \mathrm{~mm}$ sademeid ööpäeva kohta; kui kôik need tingimused ühel päeval on täidetud, siis võib pärast seda 15 päeva jooksul oodata kartuli lehemädaniku lööbimist.

Sellisel kujul on „hollandi tingimused” ilma kriitikata vastu võetud ning praktikasse rakendatud. Seejuures pole aga tungitud tingimuste sisusse ega ka vajalikul määral kontrollitud nende rakendatavust geograafiliselt erinevates kohtades. Seetõttu tekib küsimus „hollandi tunnuste” sobivusest prognoosimiseks klimaatiliselt erinevates maades. Kuidas saab tunnuste järgi, mis võivad küll olla sobivad Hollandis, prognoosida kartuli lehemädaniku ilmumist teistes maades, näiteks Eestis? Nagu me allpool näitame, osutub see mitmel põhjusel täiesti võimatuks.

Van Everdingeni poolt esitatud ilmastikutunnused võttis revideerimisele N. A. N a u m o va (13), kes õigustatult väitis, et indeks antud kujul vajab veel täiendusi ja parandusi. Naumova näitas, et van Everdingeni poolt püstitatud „hollandi tunnuste” järgi saab määrata ainult oletatavat esmakordset ehk primaarnakkust. Tegelikku lööbimismomenti aga saab kindlaks teha alles siis, kui on teada inkubatsiooniperioodi kestus, mis omakorda sõltub õhutemperatuurist. Inkubatsiooniperioodi lõpu väljaarvutamiseks koostas Naumova nomogrammi ehk arvutusgraafiku, mille abil on võimalik kindlaks teha inkubatsiooniperioodi kestust minimaalse, optimaalse ja maksimaalse õhutemperatuuri järgi. N. A. Naumova (14) esitas ka viis lööbimistingimust, mis üldjoontes ühtivad van Everdingeni tingimustega, kuid sisaldavad nõude, et järgneval päeval ei tohi maksimaalne temperatuur 
olla üle $+25^{\circ} \mathrm{C}$. Udu asemel peab Naumova vajalikuks tugevat, $4-5$ tundi püsivat kastet. See on väga oluline, sest lehemädaniku koniidid nõuavad idanemiseks küllaldasel määral niiskust. Naumova poolt teostatud uurimiste alusel koostati instruktsioon kartuli lehemädaniku prognoosimiseks. Käesoleva artikli autori poolt uuriti kartuli lehemädaniku prognoosimise võimalusi Eesti NSV-s ,hollandi tunnuste” alusel ning selle töö käigus kontrolliti ka antud instruktsiooni sobivust meie vabariigi tingimustes. Vastavad katsed teostati Tartu Riikliku Ulikooli Raadi Oppe- ja Katsemajandis* aastail 1948 ja 1949.

Vaatluste põhjal tuli teha järeldus, et prognoosimine ,hollandi tunnuste" alusel ei anna meie vabariigi tingimustes tulemusi. Lehemädaniku lööbimist erinevatel sortidel (,Frühbote”, „Ostbote”, „Jõgeva kollane”) jälgiti sõltuvalt meteoroloogilistest tingimustest, mille kohta andis andmeid Tartu Meteoroloogiajaam.

Selgus, et mainitud aastatel ei esinenud ühelgi juhul kõik ,hollandi tunnused" korraga, kuid Phytophthora infestans'i lööbimine toimus sellele vaatamata.

Uurimiste teostamisel kasutati ka J. Aamisepa (1) vaatlusi kartuli lehemädaniku esinemise kohta Jõgeval aastail 1928-1935. Tema andmeist selgus samuti, et kartuli lehemädanik lööbib enamikul juhtudel sõltumatult ,hollandi tunnustest”.

J. Aamisepp, nagu paljud teisedki autorid, - näit. N. A. Dorožkin ja A. I. Ravdo (9), A. J. Kameraz (10) jt. - seob lehemädaniku ilmumist peamiselt rikkalike sademetega juulis ja augustis. Kuid võrreldes mainitud autoritega, on Aamisepa seisukoht põhjalikumalt läbi töötatud.

J. Aamisepp uuris arvukate kartulisortide juures lehemädaniku lööbimise aegu ja jõudis järeldusele, et erinevused lööbimises on tingitud antud aasta kevade varasusest ja sademete hulgast juulis, s. t. ta väidab, et oluline on sademete hulk mitte kogu vegetatsiooniajal, vaid ainult teatud perioodil. Tema poolt toodud andmetest selgub, et aastail 1928 ja 1935 on rohkete sademete $(543,7 \mathrm{~mm}$ ja $574,3 \mathrm{~mm})$ tõttu esinenud ka rohkesti lehemädanikku.

J. Aamisepp märgib, et kui lehemädaniku rohkus on tingitud vihmastest suvedest, siis peaks oletama, et see haigus kuivadel aastatel puudub. Tema uurimised näitasid, et see oletus võiks tõesti paika pidada, sest 1933. aasta oli kuiv ja lehemädanikku ei esinenud ka peaaegu üldse, kuid samas toob ta andmeid, mille kohaselt aastad 1930, 1932 ja 1934 olid küll võrdlemisi väheste sademetega, ent lehemädanikku esines sellele vaatamata õige rohkesti (tabel 1).

Tabel 1

Sademete hulk ja lehemädaniku rohkus erinevatel aastatel (J. Aamisepa järgi)

\begin{tabular}{c|c|c}
\hline Aasta & $\begin{array}{c}\text { Sademeid } \\
\text { mm }\end{array}$ & $\begin{array}{c}\text { Lehemadaniku rohkus } \\
\text { pallides** }\end{array}$ \\
\hline 1928 & 543,7 & $4+$ \\
1930 & 250,9 & $4-$ \\
1931 & 216,2 & $2-$ \\
1932 & 242,5 & $4-$ \\
1933 & 216,1 & $4=$ \\
1934 & 186,3 & 4
\end{tabular}

* Praegune Eesti Põllumajanduse Akadeemia Raadi Oppe- ja Katsemajand.

** Kasutatud on vilepallist süsteemi. 
Seega, lähtudes nii J. Aamisepa kui ka Eesti Põllumajanduse Akadeemia botaanika, taimefüsioloogia ja fütopatoloogia kateedri poolt teostatud vaatluste tulemustest, peab järeldama, et siin on peale sademete ilmselt tegemist veel muude teguritega.

Kahtlemata tuleb arvestada, kuidas mõjuvad sademed erinevatele sortidele erineval agrofoonil. Nii näiteks on keskvalmivate sortide keskmiseks saagiks vajalik sademete hulk erinev olenevalt sellest, kas kartul kasvab liivsavistel või saviliivastel muldadel. Saviliivastel muldadel on kartulile juulis ja augustis vaja hoopis suremat hulka sademeid kui liivsavistel muldadel, sest nende muldade hügroskoopsus on erinev.

Tabel 2

Keskvalmivate sortide keskmiseks saagiks vajalik sademete hulk millimeetrites (prof. A. G. Lorch'i järgi)

\begin{tabular}{l|c|c}
\hline \multicolumn{1}{c|}{ Kuud } & $\begin{array}{c}\text { Saviliivastel } \\
\text { muldadel }\end{array}$ & $\begin{array}{c}\text { Liivsavistel } \\
\text { muldadel }\end{array}$ \\
\hline Juuni & 85 & 70 \\
Juuli & 150 & 120 \\
August & 115 & 90 \\
\hline Kogu suve jooksul & 370 & 300
\end{tabular}

Sademete hulk, mis ühel mullastikul on vajalik kartuli normaalseks arenguks, võib teistes mullastikutingimustes juba osutuda kahjulikuks, põhjustades taimes ainevahetuse häireid, mis nähtavasti muudavad taime haiguste suhtes vastuvõtlikumaks.

Ebasoodsad kasvutingimused üldse, nagu liigne sademete hulk või suhteliselt madal temperatuur, häirivad taime füsioloogilisi protsesse ning taim muutub seetõttu lehemädaniku suhtes vastuvõtlikumaks.

Uurides kartuli immuunsuse iseärasusi kartuli lehemädaniku suhtes, näitas A. I. Gretšušnikov (7), et liigne niiskus mitte ainult soodustab seene arenemist, vaid muudab ühtlasi ka peremeestaime vastuvõtlikumaks.

A. I. Gretšušnikov ja Z. S. Klimova (8) näitasid, et resistentse kartulisordi „Fitoftoroustoitšivõi” mugulate hoidmine 18 päeva vältel $0^{\circ}$-se temperatuuri juures kutsus esile mainitud sordi vastuvõtlikkuse lehemädaniku suhtes. A. I. Borghardt (5) märkis õigustatult, et on täiesti võimatu oletada parasiidi tungimist normaalselt funktsioneerivasse organismi, kui selleks puuduvad vastavad eeldused. Seda kinnitab ka M. V. Gorlenko (6), mainides, et paljude taimehaiguste levimise põhjusi tuleb näha mitte ainult teatavates, haiguse tekitajaile soodsates tingimustes, vaid ka taimele ebasoodsates tingimustes, mis põhjustavad tema haigestumist. Gorlenko rõhutab samuti, et senised raskused taimehaiguste prognoosimisel ongi olnud tingitud peamiselt sellest, et haigust tekitavat parasiiti ja peremeestaime vaadeldi eraldi, mitte aga omavahelises seoses, kusjuures peamine tähtsus omistati parasiidile.

Van Everdingenile ja Naumovale on omane antud küsimuse ühekülgne tõlgendamine - mõlemad lähtusid ainult meteoroloogilistest tingimustest, vaadeldes nende alusel parasiidi arenemise iseärasusi, ning jätsid seejuures arvestamata nii peremeestaime kui ka inimese mõju. Van Everdingen püüdis elavat loodust asendada valemiga, arvestamata seost, mis eksisteerib organismi ja keskkonna vahel ühelt poolt ning nende ja inimese vahel teiselt poolt, nagu seda õpetas V. V. Dokutšajev. Mida paremini õpime tundma organismi ja keskkonna seost, seda paremini oskame ka suunata organismi loomust, kasutades siin kõiki võimalusi väliskeskkonna 
tingimuste reguleerimiseks ja uute tingimuste loomiseks. Loomulikult ei saa inimene muuta ilmastikku, kuid ta suudab selle kahjulikule mõjule vastu töötada, võttes kasutusele vastavaid agrotehnilisi võtteid, kasutades resistentsemaid sorte jne. Pearōhk tuleb asetada soodsate kasvutingimuste loomisele, et sellega tõsta taime vastupanu haigustele.

Kartuli lehemädaniku prognoosimise indeksi tarvituselevôtmisel lähtus van Everdingen seisukohast, et on võimatu seletada vaheaja tekkimist haiguse esimeste, vaevalt märgatavate sümptoomide idanditel ilmumise ja haiguse tegeliku lööbimise vahel suve lõpul, kuid haigus ilmub vastavate meteoroloogiliste tingimuste ühtesattumisel äkki, valmis kujul. Sellist haiguse äkilist ilmumist aga ei eksisteeri, sest nakkus toimub kartulipõllul teatud vaheaegadega - haigusidud esinevad mugulates, kust haigus, olenevalt välistingimustest võib levida.

Haiguse ilmumise suhtes on tegelikult kõige ohtlikum näiliselt terve, kuid kergelt nakatatud kartuliidu, sest see tõuseb maapinnale ja annab teistele, tervetele taimedele nakkust edasi. Tugevasti nakatatud idu seevastu hävib juba mullas, enne kui ta üldse suudab maapinnale tõusta, ning pole seetõttu ohtlik teistele taimedele, sest nakkus kaob koos iduga. Kui aga selline idu siiski tõuseb maapinnale, hukkub ta seal, suutmata nakkuseks vajalike ökoloogiliste tingimuste puudumise tõttu nakkust edasi anda samas staadiumis olevatele kartuliidudele. Nakkuse edasiandmist takistab sel juhul ka kartulipealsete puudumine. Kartuli lehemädaniku ilmumisele ja arenemisele avaldab väga suurt mõju kartulipealsete tihedus, sest pealsete tiheda kasvu puhul nakatuvad kartulitaimed palju kergemini. See on tingitud peamiselt suuremast relatiivsest õhuniiskusest kartulipõõsaste vahel, mis soodustab lehemädaniku arenemist. Samal põhjusel tuleb arvestada ka pōllu umbrohtumise astet. Tegime kindlaks, et umbrohtunud põllul ilmub kartuli lehemädanik $4-5$ päeva varem kui umbrohust puhtal pōllul, mis on tingitud sellest, et rikkalik taimemass hoiab kinni kastet, udu ja vihmatilku, mis on lehemädaniku arenemisele soodne.

Oluline on ka põllu asend, s. t. kas põld asub kõrgemas või madalamas, tuule eest kaitstud kohas; nimelt on körges kohas, kus tuul juurde pääseb, nakkus tunduvalt väiksem, sest tuul kuivatab kartulilehtedel olevad vee- ja kastetilgad, mistõttu koniidid ei saa idaneda ja nakkus ei toimu nii kergesti.

Väga oluliseks teguriks, mida aga senine prognoosimisviis üldse ei arvesta, on tuul. Kartuli lehemädaniku koniidid idanevad ainult veetilgas. Nad on niiskusepuuduse suhtes väga tundlikud ning kuivas õhus hukkuvad juba 3 tunni jooksul. Tähendab, koniidid on ainult siis suutelised nakatama kartulitaime, kui selle lehed on vihmast või kastest niisked vähemalt $3-5$ tundi järjest. Kui aga selle aja jooksul esineb tuult, mis kuivatab kartulitaime lehti, siis võib nakkus ka mitte toimuda.

N. B. Novotelnova (15) ja teised autorid näitasid, et lehemädaniku koniidide idanemine zoospoorideks toimub märksa lühema aja jooksul kui idanemine idumõiguks. Nii näiteks tekivad zoospoorid kuni $+15^{\circ} \mathrm{C}$ juures juba 1 tunni jooksul, kuna idumõik tekib 5-8 tunni jooksul, vajades selleks kõrgemat temperatuuri kuni $+15^{\circ} \mathrm{C}$. Kahtlemata on väga oluline, kas tekib zoospoor vôi idumôik, sest sellest oleneb nakkuse kiirus ja haiguse levik. Eesti NSV-s esinevad juulis ja augustis suhteliselt madalad ôhutemperatuurid, mistõttu lehemädaniku levik toimub enamikul juhtudest zoospooride kaudu ja seoses sellega ka kiiresti, põhjustades haiguse massilist esinemist. Nähtavasti on sellega seletatav ka see, et Eesti NSV-s on kartuli lehemädaniku kahjustuse protsent kogu NSV Liidu territooriumil kõige suurem. 
Erakordselt suurt tähtsust kartuli resistentsuse tõstmise suhtes omab agrofoon, mida rõhutas ka akadeemik J. Eichfeld (18) oma ettekandes Leningradi oblasti põllumajanduse eesrindlaste nõupidamisel. Selles ettekandes tõi akadeemik J. Eichfeld ette tema soovitusel dr. Tšesnokovi poolt sooritatud katse, milles degenereerunud kartulite poolitatud mugulatest pandi üks pool maha tavalisele foonile, teine pool aga sõnnikuga väetatud pessa, Selgus, et tavalisel foonil kartul enamikul juhtudest haigestus, sageli koguni hukkus, sõnnikuväetisega foonil aga arenes hästi ja peaaegu ei haigestunud.

Sordi „Dr. Aamisepp" uurimine Jõgeva Riiklikus Sordiaretusjaamas näitas, et normaalfoonil toimus lehemädaniku lööbimine varakult 8. augustil, kusjuures lehestik hävis $100 \%$-liselt. Intensiivfoonil ilmus nakkus märksa hiljem - 23. augustil - ning lehestikku hävis umbes $60 \%$-liselt. Kõrgfoonil toimus lööbimine hilja, alles 12. septembril, ning lehestikku hävis võrdlemisi vähe - ainult $20 \%$ *

Viimasel ajal teostatud uurimised $(16,11)$ on näidanud, et teatud mikroelemendid (näiteks $\mathrm{B}$ ja $\mathrm{Cu}$ ) tõstavad tunduvalt kartuli resistentsust kartuli lehemädaniku suhtes. Seda kinnitavad ka Eesti Põllumajanduse Akadeemia botaanika, taimefüsioloogia ja fütopatoloogia kateedris E. Veski poolt 1954. aastal teostatud katsed vasevitrioliga $\left(\mathrm{CuSO}_{4}\right)$. Tõstes kartuli resistentsust, pidurdavad mikroelemendid sellega ühtlasi ka lehemädaniku ilmumist.

J. Aamisepp tegi katseid kartuli lehemädaniku vältimiseks ōite äranoppimise teel (2), kuid meie katsed 1951. aasta suvel ei kinnitanud seda seisukohta. Alguses oli õite äranoppimise puhul nakkust küll vähem, kuid hiljem muutus see võrdseks kõrvaldamata õitega taimede nakkusega. „Jõgeva kollasel" näiteks ilmusid õitega taimedel üksikud laigud 30. augustil, kuna äranopitud õitega taimed olid lehemädanikust puhtad. Sellele vaatamata oli 3. septembril mõlemal nakkust võrdselt, nimelt $2 \%$. Sordil „Frühbote” toimus lööbimine nii õitega kui ka õiteta taimedel üheaegselt ja lehestiku nakkuse ulatus oli mổemal juhul 100\%. „Ostbotel” oli 30. augustil õitega taimedel tabatud 3\% lehestikust, kuna õiteta taimedel esinesid ainult üksikud laigud, kuid 3. septembril oli nakkust peaaegu võrdselt - vastavalt $5 \%$ ja $4 \%$. Seega ei avalda õite äranoppimine märkimisväärset mõju kartuli lehemädaniku levimisele.

Kõike eeltoodut kokku võttes võime öelda, et kartuli lehemädaniku prognoosimine ,hollandi tunnuste" alusel osutub meie tingimustes täiesti võimatuks ning ei anna praktiliselt mingisuguseid tulemusi, kuigi ,hollandi tunnused" ja N. A. Naumova poolt soovitatud nomogramm on ära toodud paljudes õpikutes kui kindel alus lehemädaniku lööbimise prognoosimiseks. Nii näiteks esitab prof. V. I. Edelstein ,hollandi tunnused” teatud muudatustega oma õpikus (17), nomogramm on esitatud B. A. Brjantsevi ja T. L. Dobrozrakova raamatus (3), N. A. Naumovi töös (12) jne. See näitab, kui laialt on levinud arusaamine „hollandi tunnuste" vastuvaidlematust sobivusest kõikides tingimustes ja igal pool. Kuid on äärmiselt ebakindel lähtuda tõrje teostamisel lehemädaniku oletatavast lööbimismomendist, sest see on väga erinev, sõltudes veel paljudest teistest teguritest peale meteoroloogiliste tegurite, nagu seda on näidatud käesolevas töös.

Kõige otsustavamaks võitlusvahendiks kartuli lehemädaniku vastu on tegelikult profülaktika - haigust tuleb niipalju kui võimalik vältida. Seda saavutatakse kõigepealt sellega, et hoolitsetakse terve, haigustest vaba seemnematerjali eest ja täidetakse kõiki vajalikke agrotehnilisi nõudeid kartulikasvatuse alal. Uldiselt tuleb kasvatada võimalikult rohkem lehe-

* R. Tammelt 1952, aastal saadud andmed. 
mädanikukindlamaid sorte. Oluline on ka kartuli õige ületalve säilitamine hoidlates ja kuhilates, millega välditakse kartuli nakatumist igasugustesse mädanikesse.

Väga tõhusaks vahendiks lehemädaniku vältimiseks või selle arengu pidurdamiseks on kartulipealsete pritsimine $1 \%$-lise bordoovedelikuga, mis ühtlasi tunduvalt tõstab ka saaki. Pritsimine peab toimuma enne vagude kattumist kartulipealsetega; pritsimiseks tuleb valida kuiv ilm, sest vastasel korral peseb vihm bordoovedeliku kartulipealsetelt maha. Pritsimist tuleb teostada kolm korda kaheksapäevaste vaheaegadega.

Olaltoodud abinõud vähendavad tunduvalt kartuli lehemädaniku kahjustuse ulatust ja tõstavad kartuli saaki, ilma et oleks vaja kasutada prognoosi, mis nõuab küllaltki keerulisi kohapealseid vaatlusi, andmata seejuures soovitud tulemusi.

Eesti Pôllumajanduse Akadeemia

Saắus toimetusse 4. XII 1954

\section{KIRJANDUS - ЛИTEPATYPA}

1. J. A a m i s e p p, Vōrdlevaid uurimusi kartulisortidega Eestis, Tartu, 1939.

2. J. A a m is e p p, Kartuli õite murdmise mõju mugulasaagile, Tartu, 1947.

3. B. Brjantsev, T. Dobrozrakova, Taimekaitse, Tallinn, 1951.

4. E. van Everdingen, Het verband tusschen de weersgesteldheid en de Aardapelziekte (Phytophthora infestans), Tiidschrift over Plantenziekten, 32, 1926, p. $129-140$.

5. А. И. Борггардт, Явление слабого промерзания кроны плодовых деревьев, Труды Института южн. плодово-ягодн. хозяйства, 20, 1934.

6. М. В. Горленко, Болезни растений и внешняя среда, Москва, 1950.

7. А. И. Гречушников, Значение пероксидазы в иммунитете картофеля к Phytophthora infestans, Доклады АН CССР, XXV, 3, 1939.

8. А. И. Гречушников, 3. С. Климова, Влияние предварительных охлаждений картофеля на его устойчивость к Phytophthora infestans de Bary, Вестник по овощеводству и картофелю, № 2, 1940.

9. Н. А. Д оро жкин и А. И. Р а в до, Порайонная характеристика заболеваний картофеля в БССР, АН БССР, Минск, 1933.

10. А. Я. К а ме ра з, Агротехника высоких урожаев картофеля, М.-Л., 1954.

11. Ф. Е. Маленев, Повышение урожая и устойчивости картофеля к болезням путем применения микроэлементов, Сборник «Достижения науки - сёльскохозяйственному производству», Ленинград, 1952.

12. Н. А. Н а ум ов, Болезни сельскохозяйственных растений, М.-Л., 1952.

13. Н. А. Н аумова, О прогнозе появления Phytophthora infestans на картофеле, «Защита растеннй», № 3, 1935.

14. Н. А. Н а у мов а, Инструкция по сигнализации сроков опыливаний и опрыскиваннй картофеля протнв фитофторы, М.-Л., 1937.

15. Н. С. Новотельнова, Влияние температуры и влажности на прорастание конидий Phytophthora infestans (Mont) de Bary, «Защита растений», № $12,1937$.

16. Қ. Сухоруков и Е. Клинг, Действие меди на картофельное растение, Доклады АН CCCP, XVII, 6, 1945.

17. В. И. Эдель ш те й н, Овощеводство, М., 1953.

18. И. Г. Эйхфельд, Итоги августовской сессии Всесоюзной Академии сельскохозяйственных наук им. В. И. Ленина и задачи работников сельского хозяйства Ленинградской области. Сборник «Мичуринское учение - в практику сельскохозяйственного производства». Материалы ленинградского областного совещания передовиков сельского хозяйства, Ленинград, 1948. 


\title{
О ПРОГНОЗЕ ПОЯВЛЕНИЯ ФИТОФТОРЫ КАРТОФЕЛЯ (Phythophthora infestans de Bary)
}

\author{
А. Х. МАРЛАНД, \\ доктор биологических наук
}

Резюме

Своевременное проведение мероприятий по борьбе с болезнями растений является одним из средств обеспечения высоких урожаев сельскохозяйственных культур. Появление фитофторы картофеля (Phytophthora infestans) уже давно ставилось исследователями в зависимость от соответствующих условий погоды. Первая попытка прогноза появления фитофторы картофеля была сделана ван Эвердингеном $\left({ }^{4}\right)$, который установил так называемые «голландские приметы», включающие следующие условия: в течение 15 дней, предшествующих появлению фитофторы, должен быть день, когда: 1) ночью туман держится не менее четырех часов подряд; 2) минимальная температура ночью не ниже $+10^{\circ}$; 3 ) средняя облачность следующего за этой ночью дня 0,8 или выше; 4) на следующий день выпадает не менее 0,1 мм осадков. В таком виде, без критической оценки, указанные «приметы» вошли в фитопатологическую практику и рекомендуются в ряде современных учебников, иногда с незначительными изменениями.

Н. А. Наумова (13) занялась проверкой этих «примет» в условнях СССР и пришла к выводу, что «приметы» нуждаются в уточнении и доработке. Она полагала, что по «приметам» можно ориентировочно установить день первичной инфекции, но для установления времени проявления инфекции необходимо знать продолжительность инкубационного периода, которая зависит от температуры. Она разработала соответствующую номограмму для вычисления продолжительности инкубационного периода, а также инструкцию по сигнализации сроков опрыскиваний картофеля против фитофторы $\left({ }^{14}\right)$.

Мы проверили возможность применения «голландских примет» и указанной инструкции в условиях Әстонской ССР. Опыты велись в 1948 и 1949 году близ города Тарту, в Учебно-опытном хозяйстве Тартуского государственного университета *, с тремя сортами картофеля - Фрюботе, Остботе и Йыгеваский желтый. Наблюдения за появлением фитофторы велись на основе метеорологических данных, полученных от Тартуской метеорологической станции.

Мы установили, что появление фитофторы картофеля в эти годы произошло вне всякой связи с «голландскими приметами». Нами были использованы также данные наблюдений Ю. Аамисеппа (1) за появлением фитофторы картофеля, проведенных им на большом количестве сортов картофеля в Иыгева в период 1928-1935 годов. Выяснилось, что фнтофтора появлялась большей частью независимо от указанных примет.

Некоторые авторы $\left({ }^{9,10}\right)$ считают появление фитофторы исключительно следствием выпадения обильных осадков в июле и августе. Оказывается, что такая зависимость не всегда существует. Необходимо учитывать также и многие другие сопутствующие факторы, например влияние осадков на различные сорта картофеля при различных почвенных условиях. Количество осадков, нормальное для қартофеля одного и того же сорта на суспесях, может оказаться вредным на суглинках. Неблагоприятные

* В настоящее время Учебно-опытное хозяйство Эстонской сельскохозяйственной академин. 
условия среды обусловливают нарушения в физиологических процессах растения и тем самым создают условия для восприимчивости к болезням. На это указывают А. И. Борггардт $\left({ }^{5}\right)$, А. И. Гречушников $\left({ }^{7}\right)$, А. И. Гречушников и 3. С. Климова $\left({ }^{8}\right)$, М. В. Горленко $\left({ }^{6}\right)$ и др.

Ван Эвердинген в своей работе недостаточно учитывал существование взаимосвязи и взаимообусловленности в процессах, происходящих в природе, а также роль воздействия человека на эти процессы. Он полагал, что существует разрыв во времени между появлением первых симптомов болезни на ростках картофеля и окончательным проявлением болезни в конце лета, и считал, что болезнь появляется внезапно, согласно его индексу. Но это положение в корне неправильно, так как инфекция фитофторы картофеля на поле развивается с некоторыми промежутками в зависимости от экологических условий. Массовое же появление и распространение инфекции приурочивается к моменту смыкания ботвы, т. е. к тому времени, когда создаются наилучшие экологические условия для гриба. Большое влияние оказывают на появление и развитие фитофторы состояние густоты ботвы, засоренность поля и другие факторы, участвующие в создании микроклимата, который способствует развитию фитофторы или, наоборот, тормозит ее развитие. Особое значение имеет агрофон, как средство повышения устойчивости картофеля к фитофторе, как на это указывает академик И. Г. Эйхфельд $\left({ }^{18}\right)$. Это положение подтвердили опыты, проведенные на Иыгеваской государственной селекционной станции, например, с сортом картофеля Д-р Аамисепп. Устойчивость к фитофторе можно также повысить путем применения различных микроэлементов $(11,16)$.

Из сказанного ясно вытекает, что прогноз появления фитофторы картофеля лишь на основе «голландских примет» является в наших условиях неэффективным.

Основным условием в борьбе с фитофторой является выполнение всех агротехнических мероприятий с целью оздоровления семенного материала картофеля. Необходимо производить отбор здоровых клубней для посадки и опрыскивание картофеля перед смыканием ботвы $1 \%$ раствором бордосской жидкости; опрыскивание следует проводить троекратно, через каждые 8 дней. Проведение указанных мероприятий будет способствовать значительному снижению потерь от фитофторы картофеля.

Эстонская сельскохозяйственная академия

Поступила в редакцию 4 XII 1954 